\title{
The surface properties of aluminated meso-macroporous silica and its catalytic performance as hydrodesulfurization catalyst support
}

\author{
Zhi-Gang Wang ${ }^{1} \cdot$ Jia-Ning Pei ${ }^{1} \cdot$ Sheng-Li Chen ${ }^{1} \cdot$ Zheng Zhou $^{1} \cdot$ \\ Gui-Mei Yuan $^{1} \cdot$ Zhi-Qing Wang $^{2} \cdot$ Guo-Qiang Ren ${ }^{2} \cdot$ Hong-Jun Jiang ${ }^{2}$
}

Received: 21 October 2016/Published online: 5 April 2017

(c) The Author(s) 2017. This article is an open access publication

\begin{abstract}
Aluminated mesoporous silica was prepared by multiple post-grafting of alumina onto uniform mesoporous $\mathrm{SiO}_{2}$, which was assembled from monodisperse $\mathrm{SiO}_{2}$ microspheres. Hydrodesulfurization (HDS) catalyst was prepared by loading $\mathrm{Ni}$ and Mo active components onto the aluminated uniform mesoporous $\mathrm{SiO}_{2}$, and its HDS catalytic performance was evaluated using hydrodesulfurization of dibenzothiophene as the probe reaction at $300{ }^{\circ} \mathrm{C}$ and 6.0 MPa in a tubular reactor. The samples were characterized by $\mathrm{N}_{2}$ physisorption, scanning electronic microscopy, Fourier transform infrared spectrum, X-ray diffraction (XRD), temperature-programmed desorption of ammonia $\left(\mathrm{NH}_{3}-\mathrm{TPD}\right),{ }^{27} \mathrm{Al}$ nuclear magnetic resonance $\left({ }^{27} \mathrm{Al}-\mathrm{NMR}\right)$ and high-resolution transmission electron microscopy (HRTEM). The results showed that the $\mathrm{Si}-\mathrm{OH}$ group content of $\mathrm{SiO}_{2}$ was mainly dependent on the pretreatment conditions and had significant influence on the activity of the NiMo catalyst. The surface properties of the aluminated $\mathrm{SiO}_{2}$ varied with the $\mathrm{Al}_{2} \mathrm{O}_{3}$-grafting cycles. Generally after four cycles of grafting, the aluminated $\mathrm{SiO}_{2}$ behaved like amorphous alumina. In addition, plotting of activity of NiMo catalysts supported on aluminated mesomacroporous silica materials against the $\mathrm{Al}_{2} \mathrm{O}_{3}$-grafting cycle yields a volcano curve.
\end{abstract}

Sheng-Li Chen

slchen@cup.edu.cn

1 State Key Laboratory of Heavy Oil Processing, College of Chemical Engineering, China University of Petroleum, Beijing 102249, People's Republic of China

2 Shanghai Petrochemical Company of Sinopec, Jinshan, Shanghai 200540, People's Republic of China

Edited by Xiu-Qin Zhu
Keywords Aluminum grafting · Hydrodesulfurization . Surface properties $\cdot$ Catalyst support $\cdot \mathrm{SiO}_{2}$

\section{Introduction}

The demand for more environmentally friendly petroleum products with lower sulfur content is growing due to environmental problems caused by $\mathrm{SO}_{x}$ emissions. Therefore, development of new catalysts with high hydrodesulfurization (HDS) activity is required. Previous investigations (Breysse et al. 2003, 2008) indicate that the nature and characteristics of catalyst support have significant influence on the performance of HDS catalyst. Generally, for industrial NiMo and CoMo HDS catalysts, the supports are usually $\gamma-\mathrm{Al}_{2} \mathrm{O}_{3}$ or aluminosilicates rather than pure $\mathrm{SiO}_{2}$, mainly because of the stronger support-metal interaction and subsequent better HDS activity of $\mathrm{Al}_{2} \mathrm{O}_{3}$ supported catalyst than that of $\mathrm{SiO}_{2}$-supported catalyst (Scheffer et al. 1988). Ordered mesoporous $\mathrm{Al}_{2} \mathrm{O}_{3}$ is particularly suited as catalyst support due to its suitable surface and textural properties (Venezia et al. 2010; Morris et al. 2008). Therefore, a number of researchers have aimed to directly synthesize ordered mesoporous alumina (Bagshaw and Pinnavaia 1960; Yada et al. 1997; Cabrera et al. 1999; Márquez-Alvarez et al. 2008). However, the ordered mesoporous alumina obtained by direct synthesis has some shortcomings like the complexity of the synthesis process, lack of reproducibility, low thermal stability at high temperature, structural non-uniformity and wide pore distribution (Cheralathan et al. 2008). Fortunately, one alternative route to prepare ordered mesoporous alumina is available, that is, grafting alumina onto ordered $\mathrm{SiO}_{2}$ mesoporous materials. This alternative method has distinct advantages over direct synthesis with respect to 
reproducibility, structural ordering and thermal stability (Mokaya and Jones 1999; Mokaya 1997).

Up to now, various pure silica mesoporous materials, such as MCM-41 (Goldbourt et al. 2002; Landau et al. 2001), SBA-15 (Zukal et al. 2008; Baca et al. 2008) and KIT-1 (Ryoo and Kim 1997; Jun and Ryoo 2000), have been employed as templates in many investigations concerning alumination of $\mathrm{SiO}_{2}$ surfaces through grafting technology. Several researchers have investigated the HDS performance of catalysts supported on alumina-grafted materials. Klimova et al. (2003) found that a catalyst with a higher content of alumina has lower HDS activity, and concluded that over strong metal-support interaction, caused by incorporation of alumina in MCM- 41 , made the reduction and sulfidation of the active component more difficult. However, in the study of the effect of incorporation of alumina on HDS activity of NiMo/SBA-15 catalysts, it was found that the blockage of catalyst pores by alumina could lead to significant decline in activity in the case of high content of alumina (Rayo et al. 2009). On the one hand, owing to the small pore size of these molecular sieves, the pore structure probably suffered from the incorporation of alumina. On the other hand, the surface property is significantly affected by the incorporation of alumina. Therefore, it is difficult ascertain which is the main cause for the decrease in HDS activity. Fortunately, our research group has prepared $\mathrm{SiO}_{2}$ opal by ordered facecentered cubic packing of monodisperse silica microspheres (Zhou et al. 2012a, b). The ordered compact of $\mathrm{SiO}_{2}$ opal with a high coordination number has very uniform pore size distribution, and the pore size can be tuned according to the needs of experiments by changing the diameter of the monodisperse $\mathrm{SiO}_{2}$ microspheres. Hence, $\mathrm{SiO}_{2}$ opals with larger pore size are more suitable materials for the grafting of multilayer alumina, since larger pore sized opal has better pore structure stability against the amount of grafted alumina, than MCM-41 or SBA-15. In addition, the content of silanol groups on the surface of template porous $\mathrm{SiO}_{2}$ opal is supposed to have a great influence on the post-synthesis of alumination (Mokaya and Jones 1999; Li et al. 2001; Zhao et al. 1997), and the content of the silanol groups mainly depends on pretreatment conditions, such as calcination temperature and whether or not there has been a hydrothermal treatment. However, very few researchers have aimed to investigate the effect of the content of silanol groups of template porous $\mathrm{SiO}_{2}$ on HDS activity of catalyst using aluminated $\mathrm{SiO}_{2}$ as catalyst support.

In the present work, the effects of pretreatment conditions of the $\mathrm{SiO}_{2}$ materials and the $\mathrm{Al}_{2} \mathrm{O}_{3}$-grafting cycle on the surface properties of aluminated $\mathrm{SiO}_{2}$ opal materials were investigated. In order to ascertain the relationship between the HDS activity and the surface property of the aluminated $\mathrm{SiO}_{2}$ used as catalyst support, the catalytic performance of NiMo catalysts supported on these aluminated $\mathrm{SiO}_{2}$ opal materials was tested using the HDS of dibenzothiophene (DBT) as probe reaction.

\section{Experimental}

\subsection{Preparation of $\mathrm{SiO}_{2}$ opal materials and reference alumina}

Monodisperse $\mathrm{SiO}_{2}$ microspheres were synthesized through hydrolysis and condensation of tetraethyl orthosilicate (98\%, J\&K) in alcohol $(99.7 \%$, Sinopharm Chemical Reagent) and in the presence of water and ammonia by the seed particle growth method. Detailed descriptions of the synthesis procedures were reported in the previous papers of our research group (Chen et al. 1996; Liu et al. 2009; Chen 1998). In this work, monodisperse $\mathrm{SiO}_{2}$ microspheres with diameters of 100,250 and $500 \mathrm{~nm}$ were prepared. First, $\mathrm{SiO}_{2}$ opals were obtained by ordered packing of $\mathrm{SiO}_{2}$ microspheres, then the assembled $\mathrm{SiO}_{2}$ opals were calcined at three temperatures in the range of $500-900{ }^{\circ} \mathrm{C}$ for $2 \mathrm{~h}$, and finally these $\mathrm{SiO}_{2}$ opals were hydrothermally treated at $220{ }^{\circ} \mathrm{C}$ for $5 \mathrm{~h}$ to recover the surface silanol groups which were lost during the calcination. The pretreatment of the $\mathrm{SiO}_{2}$ opal includes the calcination and hydrothermal treatment. In addition, a reference alumina, denoted as $\left(\mathrm{Al}\left(\mathrm{NO}_{3}\right)_{3}-\mathrm{C}\right)$, was prepared by calcination of $\mathrm{Al}\left(\mathrm{NO}_{3}\right)_{3-}$ $9 \mathrm{H}_{2} \mathrm{O}$ (99\%, Sinopharm Chemical Reagent) in static air at $500{ }^{\circ} \mathrm{C}$ for $5 \mathrm{~h}$.

\subsection{Alumination of $\mathrm{SiO}_{2}$ opal materials}

In the alumination procedure, hydrothermally treated $\mathrm{SiO}_{2}$ opals were added to $0.67 \mathrm{M}$ aluminum nitrate $\left(\mathrm{Al}\left(\mathrm{NO}_{3}\right)_{3}\right)$ solution at $80{ }^{\circ} \mathrm{C}$, kept in the solution for $12 \mathrm{~h}$ and then filtered to remove the solution. To remove the $\mathrm{Al}\left(\mathrm{NO}_{3}\right)_{3}$ solution in the pores of the $\mathrm{SiO}_{2}$ opals, the filtered $\mathrm{SiO}_{2}$ opals were washed three times with distilled water. The $\mathrm{SiO}_{2}$ opals were then dried at $100{ }^{\circ} \mathrm{C}$ for $6 \mathrm{~h}$ and calcined in static air at $500{ }^{\circ} \mathrm{C}$ for $5 \mathrm{~h}$. The above steps compose one cycle of $\mathrm{Al}_{2} \mathrm{O}_{3}$ grafting, and the $\mathrm{Al}_{2} \mathrm{O}_{3}$-grafting process can be repeated several times. The sample is denoted as $m$ $\mathrm{SiO}_{2}-\mathrm{Al}-n$, where $m$ is the diameter of the monodisperse $\mathrm{SiO}_{2}$ microspheres, from which the $\mathrm{SiO}_{2}$ opal was made of, and $n$ is the number of $\mathrm{Al}_{2} \mathrm{O}_{3}$-grafting cycles. These aluminated $\mathrm{SiO}_{2}$ opal materials were used as supports for the hydrodesulfurization catalyst. 


\subsection{Catalyst preparation}

NiMo catalysts were prepared by incipient wetness coimpregnation of aqueous solutions of $\left(\mathrm{NH}_{4}\right) \mathrm{Mo}_{7} \mathrm{O}_{2} \cdot 4 \mathrm{H}_{2} \mathrm{O}$ $\left(>99 \%\right.$, Sinopharm Chemical Reagent) and $\mathrm{Ni}\left(\mathrm{NO}_{3}\right)_{2-}$ $6 \mathrm{H}_{2} \mathrm{O}(>98 \%$, Sigma-Aldrich) into catalyst support. After impregnation, the catalysts were dried at $100{ }^{\circ} \mathrm{C}$ for $6 \mathrm{~h}$ and then calcined at $500{ }^{\circ} \mathrm{C}$ for $5 \mathrm{~h}$. The active metallic component loadings in the catalysts were $5.42 \mu \mathrm{mol}$ $\mathrm{MoO}_{3} / \mathrm{m}^{2}$ support and $1.81 \mu \mathrm{mol} \mathrm{NiO} / \mathrm{m}^{2}$ support. For comparison, the reference alumina was loaded with the same loading amount of $\mathrm{MoO}_{3}$ and $\mathrm{NiO}$ by incipient wetness co-impregnation of $\left(\mathrm{NH}_{4}\right) \mathrm{Mo}_{7} \mathrm{O}_{2} \cdot 4 \mathrm{H}_{2} \mathrm{O}$ and $\mathrm{Ni}\left(\mathrm{NO}_{3}\right)_{2} \cdot 6 \mathrm{H}_{2} \mathrm{O}$ aqueous solutions. This catalyst was dried and calcined as described above. All catalysts were crushed and sieved to a size of about $0.23 \mathrm{~mm}$ before catalytic performance testing.

\subsection{Characterization of support and catalyst}

The supports and catalysts were characterized by $\mathrm{N}_{2}$ physisorption, scanning electron microscopy (SEM), X-ray diffraction (XRD), temperature-programmed desorption (TPD), ${ }^{27} \mathrm{Al}$ nuclear magnetic resonance (NMR) and highresolution transmission electron microscopy (HRTEM). $\mathrm{N}_{2}$ adsorption/desorption isotherms were measured with a Micromeritics ASAP 2020 automatic analyzer (ASAP 2020, Micromeritics, USA) at $-196{ }^{\circ} \mathrm{C}$. Specific surface areas were calculated by the BET method. The total pore volume and pore size distributions were measured by the mercury penetration method on an Autopore II 9220 mercury porosimeter using a contact angle of $140^{\circ}$. The morphology of catalysts was observed on a scanning electron microscope (Quanta 200F, FEI, USA) using an accelerating voltage of $20 \mathrm{kV}$. HRTEM micrographs were obtained by using a transmission electron microscope (JEM-2100, JEOL, Japan) operated at $200 \mathrm{kV}$. The sulfided catalysts were crushed and then ultrasonically dispersed in heptane, and the suspension was collected on carbon-coated grids. HRTEM micrographs were taken from different parts of the same sample dispersed on the microscope grid. Wideangle XRD patterns were recorded in the range of $10^{\circ}<2 \theta<85^{\circ}$ on a Bruker D8 Advance diffractometer (D8 Advance, Bruker, German), using $\mathrm{Cu} \mathrm{K} \alpha$ radiation and a goniometer speed of $1^{\circ}(2 \theta) \mathrm{min}^{-1}$. The acid sites amount and acid strength distribution were determined by the $\mathrm{NH}_{3}$-TPD. The ammonia in the effluent gas was detected by a thermal conductivity detector (TCD). Before $\mathrm{NH}_{3}$-TPD experiments, the samples were pretreated in situ at $550{ }^{\circ} \mathrm{C}$ for $50 \mathrm{~min}$ in a $\mathrm{N}_{2}$ flow in order to remove water and other contaminants. The samples were then cooled to $110{ }^{\circ} \mathrm{C}$, and a $\mathrm{N}_{2} / \mathrm{NH}_{3}$ mixture $(30 / 10 \mathrm{~mol} / \mathrm{mol})$ at a flow rate of $40 \mathrm{ml} / \mathrm{min}$ was fed for $30 \mathrm{~min}$. The desorption step was performed in a $\mathrm{N}_{2}$ stream $(30 \mathrm{~mL} / \mathrm{min})$ at a heating rate of $10{ }^{\circ} \mathrm{C} / \mathrm{min} .{ }^{27} \mathrm{Al}$ MAS NMR was carried out on a Bruker AVANCE III 600 spectrometer at a resonance frequency of $156.4 \mathrm{MHz}$ using a $4 \mathrm{~mm} \mathrm{HX}$ double-resonance MAS probe at a sample spinning rate of $15 \mathrm{kHz}$. The ${ }^{27} \mathrm{Al}$ chemical shift was referenced to $1 \mathrm{M}$ aqueous $\mathrm{Al}\left(\mathrm{NO}_{3}\right)_{3} \cdot{ }^{27} \mathrm{Al}$ MAS NMR spectra were recorded by the small flip angle technique with a pulse length of $0.5 \mu \mathrm{s}$ $(<\pi / 12)$, a $1 \mathrm{~s}$ recycle delay and 4000 scans. Fourier transform infrared spectroscopy (FTIR) was recorded on a Bruker IFS $66 \mathrm{~V}$ spectrometer in the range of $3800-600 \mathrm{~cm}^{-1}\left(4 \mathrm{~cm}^{-1}\right.$ resolution, 256 scans/spectrum $)$ using a Thermo Spectra-Tech high-temperature cell. All the spectra were recorded at $150{ }^{\circ} \mathrm{C}$ in argon after $2 \mathrm{~h}$ of pretreatment at $450{ }^{\circ} \mathrm{C}$ in argon.

\subsection{HDS activity of NiMo catalyst}

The HDS activity tests of the NiMo catalysts were carried out in a bench-scale stainless-steel tubular reactor at $300{ }^{\circ} \mathrm{C}$ and $6.0 \mathrm{MPa}$ using a sulfur-free lube base oil solution of DBT (1000 ppm of S) as HDS feedstock. The lube base oil was provided by Sinopec Shanghai Gaoqiao Petrochemical Corporation (China). Prior to catalytic HDS, the catalysts were sulfided by a mixture of $2 \mathrm{wt} \% \mathrm{CS}_{2}$ and cyclohexane with the following temperature program: reactor temperature was raised to $230{ }^{\circ} \mathrm{C}$ from room temperature at a heating rate of $7{ }^{\circ} \mathrm{C} / \mathrm{min}$ and kept at $230{ }^{\circ} \mathrm{C}$ for $3 \mathrm{~h}$; then the temperature was raised to $340{ }^{\circ} \mathrm{C}$ at a heating rate of $3{ }^{\circ} \mathrm{C} / \mathrm{min}$ and kept at $340{ }^{\circ} \mathrm{C}$ for $3 \mathrm{~h}$. The presulfiding conditions were as follows: liquid hourly space velocity (LHSV), $5 \mathrm{~h}^{-1} ; \mathrm{H}_{2} / \mathrm{Oil}(\mathrm{v} / \mathrm{v})$ ratio, 200; operation pressure, 6.0 MPa. After sulfidation, the stream was switched from sulfiding agent to HDS feedstock and maintained for $20 \mathrm{~h}$ to achieve catalyst stability, and the hydrodesulfurized sample was collected at the appropriate time (the time interval depended on the LHSV). Then, these samples were washed with $5 \mathrm{wt} \%$ sodium hydroxide solution three times to remove the dissolved $\mathrm{H}_{2} \mathrm{~S}$. The sulfur content in the samples was measured by using a THA-2000S UV-induced fluorescence sulfur analyzer (Taizhou Jinhang Analytical Instruments Co. Ltd., China).

\section{Results and discussion}

\subsection{Support and catalyst characterization}

The pore structure characterization of supports and their NiMo catalysts is shown in Tables 1 and 2, respectively. It can be seen that the three $\mathrm{SiO}_{2}$ opal supports without pretreatment had almost the same total pore volume (about $0.23 \mathrm{~cm}^{3} / \mathrm{g}$ ), but their average pore diameter and specific 
Table 1 Pore structure characterization of catalyst supports

\begin{tabular}{|c|c|c|c|c|c|c|c|c|}
\hline Samples & $D_{\mathrm{m}}, \mathrm{Nm}$ & $\mathrm{CT},{ }^{\circ} \mathrm{C}$ & $\mathrm{HT}$ & GC & Alumina content, $\mathrm{g} / 100 \mathrm{~m}^{2} \mathrm{SiO}_{2}$ & $\mathrm{SSA}, \mathrm{m}^{2} / \mathrm{g}$ & $V_{\mathrm{p}}, \mathrm{cm}^{3} / \mathrm{g}$ & $d_{\mathrm{p}}, \mathrm{nm}$ \\
\hline A & 100 & - & - & - & - & 34.8 & 0.22 & 25.2 \\
\hline A-500-H-2 & 100 & 500 & $\mathrm{Y}$ & 2 & 0.053 & 32.5 & 0.21 & 25.8 \\
\hline A-700-2 & 100 & 700 & $\mathrm{~N}$ & 2 & 0.042 & 30.1 & 0.21 & 27.9 \\
\hline A-700-H-2 & 100 & 700 & $\mathrm{Y}$ & 2 & 0.052 & 29.8 & 0.21 & 28.1 \\
\hline A-900-H-2 & 100 & 900 & $\mathrm{Y}$ & 2 & 0.031 & 27.3 & 0.19 & 27.8 \\
\hline A-700-H-4 & 100 & 700 & $\mathrm{Y}$ & 4 & 0.088 & 30.4 & 0.20 & 26.3 \\
\hline B & 250 & - & - & - & - & 18.8 & 0.23 & 48.9 \\
\hline B-700-H-4 & 250 & 700 & $\mathrm{Y}$ & 4 & - & 17.8 & 0.22 & 49.4 \\
\hline $\mathrm{C}$ & 500 & - & - & - & - & 9.8 & 0.23 & 93.9 \\
\hline C-700-H-4 & 500 & 700 & $\mathrm{Y}$ & 4 & - & 9.9 & 0.23 & 93.0 \\
\hline
\end{tabular}

$D_{\mathrm{m}}$ is the diameter of microspheres, $\mathrm{nm} ; C T$ is the calcination temperature, ${ }^{\circ} \mathrm{C} ; H T$ is hydrothermal treatment; $G C$ is the grafting cycles of alumina; $d_{\mathrm{p}}$ is the average pore diameter, $\mathrm{nm} ; V_{\mathrm{p}}$ is the pore volume, $\mathrm{cm}^{3} / \mathrm{g} ; S S A$ is the specific surface area, $\mathrm{cm}^{2} / \mathrm{g}$. Alumina content was measured by EDX
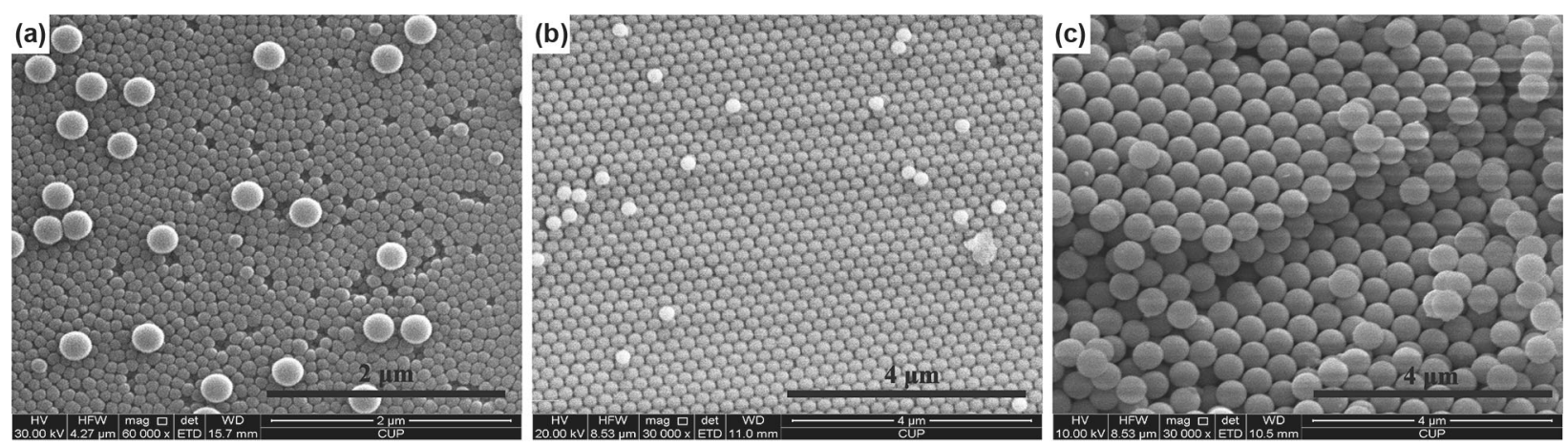

Fig. 1 SEM images of NiMo catalysts with microspheres diameters of $100 \mathrm{~nm}(\mathbf{a}), 250 \mathrm{~nm}(\mathbf{b})$, and $500 \mathrm{~nm}(\mathbf{c})$

Table 2 Pore structure properties of NiMo catalysts

\begin{tabular}{lrll}
\hline Sample & $d_{\mathrm{p}}, \mathrm{nm}$ & $V_{\mathrm{p}}, \mathrm{cm}^{3} / \mathrm{g}$ & $S S A, \mathrm{~m}^{2} / \mathrm{g}$ \\
\hline NiMo/A-700-H-4 & 27.5 & 0.19 & 26.2 \\
NiMo/B-700-H-4 & 49.4 & 0.20 & 16.2 \\
NiMo/C-700-H-4 & 100.3 & 0.23 & 9.2 \\
NiMo/Al $\left(\mathrm{NO}_{3}\right)_{3}-\mathrm{C}$ & 4.9 & 0.12 & 95.2 \\
\hline
\end{tabular}

surface area were different from each other (Table 1). Due to the shrinkage of the $\mathrm{SiO}_{2}$ microspheres during calcination and sealing of the micropores on the surface of the $\mathrm{SiO}_{2}$ microspheres during hydrothermal treatment, the specific surface area of $\mathrm{SiO}_{2}$ opal which was calcined and hydrothermally treated had declined slightly. Additionally, the pore structure did not change significantly after successive $\mathrm{Al}_{2} \mathrm{O}_{3}$-grafting steps and NiMo impregnation (Tables 1 , 2; Fig. 1), indicating that the well-defined pore structure of the original $\mathrm{SiO}_{2}$ opals was still well maintained after several cycles of $\mathrm{Al}_{2} \mathrm{O}_{3}$ grafting and NiMo impregnation. Figure 2 shows that catalysts were opal-like materials with facecentered cubic packing of monodisperse nonporous spheres.

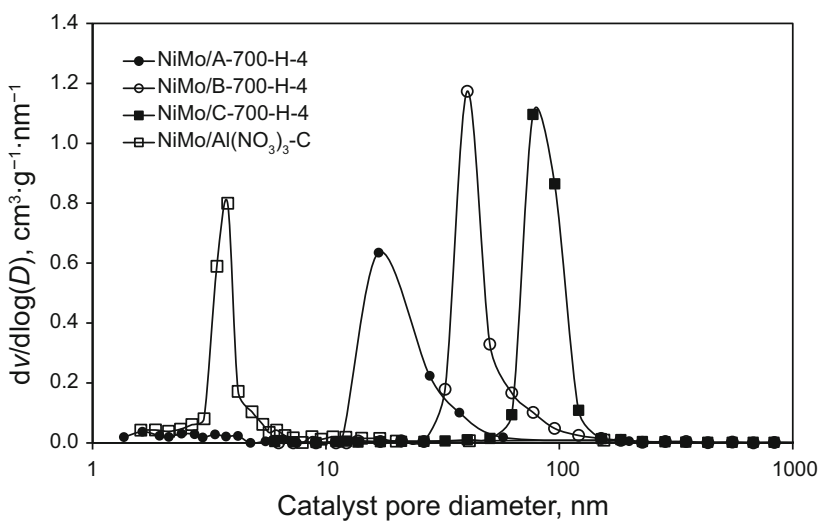

Fig. 2 Pore size distribution of four NiMo catalysts

Clearly, the well-defined pore structure was not damaged by NiMo impregnation and $\mathrm{Al}_{2} \mathrm{O}_{3}$-grafting treatment.

The silanol group of the samples pretreated at different conditions was evaluated by FTIR spectroscopy (Fig. 3). According to the report by Brandriss and Margel (1993) the absorbance at approximately $3750 \mathrm{~cm}^{-1}$ and at the range approximately from 3265 to $3645 \mathrm{~cm}^{-1}$ was assigned to 


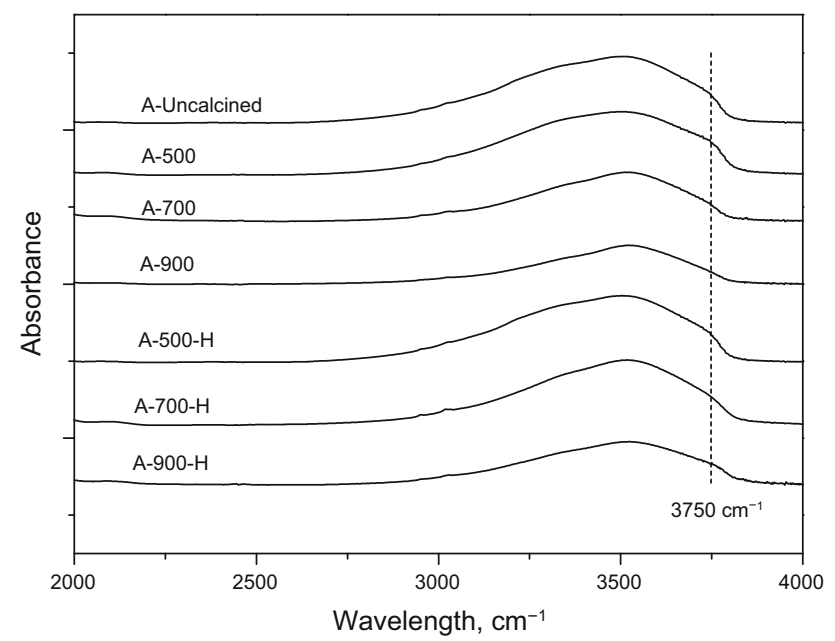

Fig. 3 Infrared spectra for $\mathrm{SiO}_{2}$ opal, assembled from 100-nm microspheres pretreated at different conditions

free silanol and chemisorption of water through silanol group, respectively. Upon heating, the intensity of the absorbance belonging to free silanol and the chemisorption of water began to decrease, indicating that the surface silanol group started to condense and eliminate water. After hydrothermal treatment, the silanol group can be almost completely recovered if the calcination temperature is below $500{ }^{\circ} \mathrm{C}$; the silanol group could be partly recovered if the calcination temperature above $500{ }^{\circ} \mathrm{C}$.

The ${ }^{27} \mathrm{Al} \mathrm{NMR}$ results of this work showed that the pretreatment conditions of the $\mathrm{SiO}_{2}$ opals and the alumination procedure had a strong effect on the $\mathrm{Al}$ coordination (Fig. 4). It was reported that three distinct signals with maximum values centered at 3,34 and $56 \mathrm{ppm}$ should be assigned to octahedral $\mathrm{Al}$ (oct), pentahedral $\mathrm{Al}$ (pen) and tetrahedral $\mathrm{Al}$ (tet) atoms, respectively (Zukal et al. 2008).



Fig. $4{ }^{27} \mathrm{Al}$ NMR spectra of $\mathrm{SiO}_{2}$ opal grafted with different amounts of alumina and $\gamma-\mathrm{Al}_{2} \mathrm{O}_{3}$
It can be seen that the chemical shift of the $\mathrm{Al}$ (tet) of the grafted materials was closer to that of tetrahedral $\mathrm{Al}$ in zeolite and amorphous aluminum silicate reported in literature (Klimova et al. 2003; Hensen et al. 2010; GóraMarek et al. 2005), indicating the formation of Al-O-Si bonds resulted from the grafting of $\mathrm{Al}$ atoms on the surface of $\mathrm{SiO}_{2}$ microspheres. It is noteworthy that the spectra of these $\mathrm{Al}_{2} \mathrm{O}_{3}$-grafted materials were different from those of $\gamma-\mathrm{Al}_{2} \mathrm{O}_{3}$, which consists mostly of $\mathrm{Al}($ tet $)$ and $\mathrm{Al}(\mathrm{oct})$ with a $\mathrm{Al}$ (tet)/Al(oct) atomic ratio of $3 / 7$, and the $\mathrm{Al}$ (pen) accounts for very small amount. According to the report by De Witte (De Witte et al. 1995), the Al(pen) usually exists in the interface between silica and alumina or in the amorphous silica-alumina, indicating that the local arrangement of aluminum atoms in $\mathrm{Al}_{2} \mathrm{O}_{3}$-grafted materials was different from that in bulk $\gamma-\mathrm{Al}_{2} \mathrm{O}_{3}$. In addition, the effect of calcination temperature on $\mathrm{Al}$ coordination is also found from the ${ }^{27} \mathrm{Al}$ NMR spectrum of A-700-H-2 and A-900-H-2 in Fig. 4. The Al(tet) was formed through the silanol group on the surface of the $\mathrm{SiO}_{2}$ microspheres; therefore, the content of the $\mathrm{Al}$ (tet) mainly depended on the amount of silanol group which was largely affected by the calcination temperature. Based on the results of infrared spectra (see Fig. 2), the content of silanol group of A-700$\mathrm{H}$ is higher that of $\mathrm{A}-900-\mathrm{H}$, so more $\mathrm{Al}($ tet $)$ could exist after two $\mathrm{Al}_{2} \mathrm{O}_{3}$-grafting cycles.

Further characterization of the supports was undertaken by $\mathrm{NH}_{3}$-TPD to investigate the acidity of support with different amounts of alumina, and the result is shown in Fig. 5. $\mathrm{NH}_{3}$ desorption peaks at 120-220, 220-400 and $400-550{ }^{\circ} \mathrm{C}$ represent weak, medium and strong acid, respectively, and the acidity data of them are summarized in Table 3. Table 3 shows that the pure silica support presented mostly weak acid sites originating from the

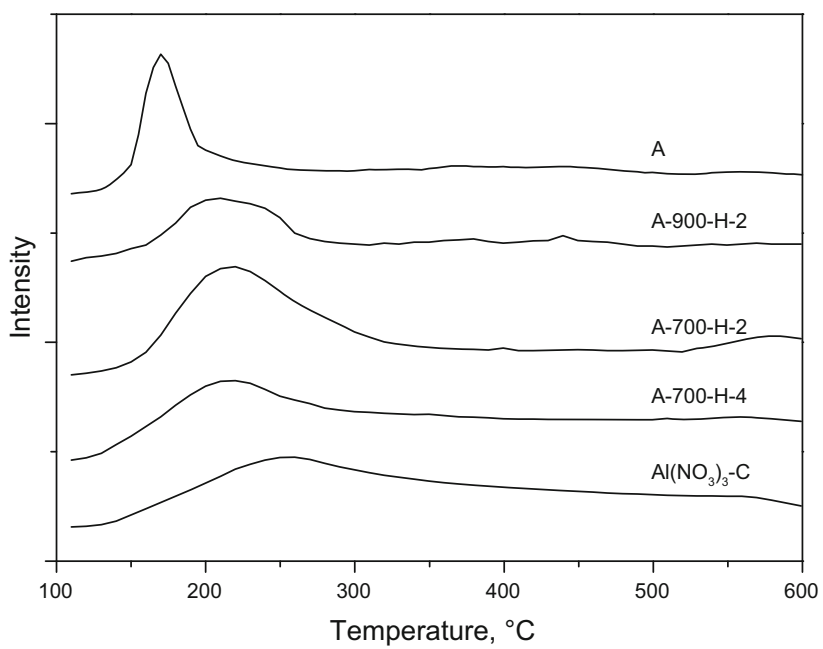

Fig. $5 \mathrm{NH}_{3}$-TPD spectra of alumina-grafted materials, parent $\mathrm{SiO}_{2}$ opal and reference alumina 
Table 3 Acidity density of the parent $\mathrm{SiO}_{2}$ opal, grafted materials and reference alumina

\begin{tabular}{lllll}
\hline Samples & \multicolumn{2}{l}{ Acidity density, $\mu \mathrm{mol} \mathrm{NH}_{3} / \mathrm{m}^{2}$} \\
\cline { 2 - 5 } & Total acid & Weak acid $110-220{ }^{\circ} \mathrm{C}$ & Medium acid $220-400{ }^{\circ} \mathrm{C}$ & Strong acid $400-600{ }^{\circ} \mathrm{C}$ \\
\hline A & 1.23 & 0.82 & 0.23 & 0.18 \\
A-900-H-2 & 1.51 & 0.51 & 0.68 & 0.32 \\
A-700-H-2 & 2.99 & 0.88 & 1.36 & 0.75 \\
A-700-H-4 & 2.29 & 0.61 & 1.10 & 0.58 \\
$\mathrm{Al}\left(\mathrm{NO}_{3}\right)_{3}-\mathrm{C}$ & 2.22 & 0.23 & 1.48 & 0.61 \\
\hline
\end{tabular}

silanol group on the surface, and only a small amount of medium and strong acid sites. However, the amorphous alumina (Sample $\mathrm{Al}\left(\mathrm{NO}_{3}\right)_{3}-\mathrm{C}$ ) presented mostly medium and strong acid sites. After two cycles of alumina grafting (Sample A-700-H-2), the alumina-grafted materials showed a significant decrease in the amount of weak acid sites, indicating that the silanol group was consumed in the reaction with aluminum species, and medium and strong acid sites were created by $\mathrm{Al}_{2} \mathrm{O}_{3}$ grafting. After four cycles of alumina grafting (Sample A-700-H-4), the total acidity decreased, possibly due to the formation of more amorphous alumina like the sample $\mathrm{Al}\left(\mathrm{NO}_{3}\right)_{3}-\mathrm{C}$. Based on the result of the ${ }^{27} \mathrm{Al}$ NMR (Fig. 4), it can be concluded that the total acidity increased first and then decreased with the grafting cycle, confirming that some of the grafted alumina atoms would be bonded with silica atoms of the silica microspheres after two-cycle grafting, but the acid sites would be covered by the alumina overlayer during the subsequent $\mathrm{Al}_{2} \mathrm{O}_{3}$ grafting. By comparing the $\mathrm{NH}_{3}-\mathrm{TPD}$ spectra (Fig. 5) of the A-700-H-2 and A-900-H-2 and infrared spectra (Fig. 3) of the A-700-H and A-900-H, it can be found that higher content of silanol group is more conducive to forming acid sites during the grafting procedure.

The supports and their corresponding NiMo catalysts were analyzed by XRD, and the results are shown in Fig. 6. No distinct diffraction peaks are observed in the XRD patterns of $\mathrm{Al}\left(\mathrm{NO}_{3}\right)_{3}-\mathrm{C}$ (Fig. 6a), indicating that amorphous alumina was formed during calcination of $\mathrm{Al}\left(\mathrm{NO}_{3}\right)_{3}$ at $500{ }^{\circ} \mathrm{C}$. The XRD patterns of $\mathrm{SiO}_{2}$ opal showed a broad signal in the $2 \theta$ range between $15^{\circ}$ and $35^{\circ}$ (samples $\mathrm{A}$ in Fig. 6a), and this was attributed to the amorphous silica (Zepeda et al. 2008; Nava et al. 2007). It is suggested that the alumina unbonded with silicon atoms of $\mathrm{SiO}_{2}$ microspheres can be regarded as amorphous alumina similar to the $\mathrm{Al}\left(\mathrm{NO}_{3}\right)_{3}-\mathrm{C}$ sample. As shown in Fig. $6 \mathrm{~b}$, no reflections belonging to molybdenum and nickel oxides are observed in the XRD patterns of the $\mathrm{NiMo} / \mathrm{Al}\left(\mathrm{NO}_{3}\right)_{3}-\mathrm{C}$ catalyst. This result indicated a good dispersion of deposited $\mathrm{Ni}$ and Mo oxide species on the support surface. For $\mathrm{NiMo} / \mathrm{SiO}_{2}$ catalyst, besides the peaks from the support, some peaks of molybdenum oxide appeared at $2 \theta$ of $12.7^{\circ}$,


Fig. 6 XRD patterns for supports (a) and corresponding NiMo catalysts (b)

$22.7^{\circ}$ and $33.4^{\circ}$ (JCPDS (Joint Committee on Powder Diffraction Standards) card 35-609). An additional reflection peak appeared at $2 \theta$ of $25.6^{\circ}$, indicating the presence of $\beta-\mathrm{NiMo}_{4}$ phase (JCPDS card 21-0868). However, in the case of $\mathrm{NiMo} / \mathrm{Al}_{2} \mathrm{O}_{3}$-grafted $\mathrm{SiO}_{2}$ catalyst, no reflections of $\mathrm{MoO}_{3}$ and $\beta-\mathrm{NiMo}_{4}$ are found, indicating that the incorporation of alumina in the supports enhanced the dispersion of active components of the catalysts.

\subsection{Catalytic activity in hydrodesulfurization of dibenzothiophene}

In the present study, the catalytic activity of NiMo catalyst using alumina-grafted $\mathrm{SiO}_{2}$ as support was tested using the HDS of dibenzothiophene (DBT) in a fixed-bed tubular reactor as the probe reaction. The HDS catalytic activity of NiMo catalysts supported on parent $\mathrm{SiO}_{2}$ opals, and amorphous alumina was also tested for comparison purposes. Surface area hourly space velocity (SHSV) was applied to describe the ratio of flow rate of liquid feedstock to the catalyst surface area. According to the literature (Chen et al. 2005; Chen and Ring 2004), HDS reactions of individual compounds follow first-order kinetics, so the 
material balance of the isothermal and plug-flow reactor is given by Eq. (1).

$\ln \left(\frac{C_{0}}{C_{t}}\right)=k \cdot S H S V^{-1}$

$S H S V=\frac{Q}{S}$

where $C_{0}$ and $C_{t}$ is the sulfur concentration in the feedstock and product stream, respectively, ppm; $k$ is the pseudofirst-order reaction rate constant, $\mathrm{m} \mathrm{s}^{-1} ; Q$ is the feedstock flow rate, $\mathrm{m}^{3} \mathrm{~s}^{-1} ; S$ is the surface area of the catalyst loaded in the reactor, $\mathrm{m}^{2}$.

For the HDS catalytic performance testing, SHSV was varied through changing the $Q$, the liquid effluents from the reactor were collected, and their sulfur content was measured. The relationship between $\ln \left(C_{0} / C_{t}\right)$ and $S H S V^{-1}$ is shown in Fig. 7. The best fit straight lines of $\ln \left(C_{0} / C_{t}\right)$ versus $S H S V^{-1}$ were obtained, and the slope of the straight line was the $k$. Three $\mathrm{SiO}_{2}$ opals, prepared with 100,250 and $500 \mathrm{~nm} \mathrm{SiO} \mathrm{Si}_{2}$ microspheres, were employed as templates to fabricate NiMo catalysts. The $k$ of various NiMo catalysts supported on $\mathrm{SiO}_{2}$ opal grafted with different amounts of $\mathrm{Al}_{2} \mathrm{O}_{3}$ is calculated and presented in Fig. 8, and the $\mathrm{n}$ in the legend at the top left corner represent the $\mathrm{Al}_{2} \mathrm{O}_{3}$-grafting cycles. It can be found that the catalytic activities of all the NiMo catalysts supported on aluminated $\mathrm{SiO}_{2}$ opals were significantly higher than those of NiMo catalysts supported on parent $\mathrm{SiO}_{2}$ opals. In addition, the activity of NiMo catalysts supported on the aluminated $\mathrm{SiO}_{2}$ yielded a volcano curve as a function of the $\mathrm{Al}_{2} \mathrm{O}_{3}$ grafting cycles. According to the results of ${ }^{27} \mathrm{Al}$ NMR in Fig. 4, a certain amount of $\mathrm{Al}$ was implanted within the outer surface of the silica microspheres during the grafting



Fig. 7 Relationship between $S H S V^{-1}$ and $\ln \left(C_{0} / C_{t}\right) \quad\left(300{ }^{\circ} \mathrm{C}\right.$, 6.0 $\left.\mathrm{MPa}, \mathrm{H}_{2} / \mathrm{Oil}(\mathrm{v} / \mathrm{v})=800\right)$



Fig. 8 Reaction rate constant $k$ of various NiMo catalysts supported on Al-grafted materials with different amounts of alumina $\left(300{ }^{\circ} \mathrm{C}\right.$, 6.0 $\left.\mathrm{MPa}, \mathrm{H}_{2} / \mathrm{Oil}(\mathrm{v} / \mathrm{v})=800\right)$

process, and amorphous aluminum silicate was formed. Then the content of amorphous aluminum silicate gradually increased with the grafting cycles. Therefore, the activities of the catalysts supported on aluminated $\mathrm{SiO}_{2}$ began to increase till it reached a maximum. The maximum $k$ of the three NiMo catalysts was $5.64 \mathrm{~m} \mathrm{~s}^{-1}$ for NiMo/A$700-\mathrm{H}-2,6.32 \mathrm{~m} \mathrm{~s}^{-1}$ for NiMo/B-700-H-2 and $7.60 \mathrm{~m} \mathrm{~s}^{-1}$ for $\mathrm{NiMo} / \mathrm{C}-700-\mathrm{H}-2$, respectively. Excessive $\mathrm{Al}$ grafting resulted in the formation of amorphous alumina that caused a significant decrease in $k$. As a result, the $k$ of the three NiMo catalysts supported on the $\mathrm{SiO}_{2}$ with four $\mathrm{Al}_{2} \mathrm{O}_{3}$ grafting cycles was almost equal to that of NiMo catalyst



Fig. 9 Effect of pretreatment conditions on the reaction rate constant $k$ of NiMo catalysts $\left(300{ }^{\circ} \mathrm{C}, 6.0 \mathrm{MPa}, \mathrm{H}_{2} / \mathrm{Oil}(\mathrm{v} / \mathrm{v})=800\right)$ 
supported on $\mathrm{Al}\left(\mathrm{NO}_{3}\right)_{3}$-C. Several researchers (Landau et al. 2001; Rayo et al. 2009) have reported the catalytic activity of catalysts supported on $\mathrm{Al}_{2} \mathrm{O}_{3}$-grafted materials, and they found that when the content of the alumina exceeds a certain level, the activity of the catalysts began to decrease significantly. In their studies, molecular sieves were used, and the pore textural properties of molecular sieves were prone to being damaged when a high content of alumina is introduced. Therefore, the decrease in the activity may be attributed to this damage of the textural properties. In the present research work, the textural properties of the aluminated $\mathrm{SiO}_{2}$ changed only slightly with the grafting cycles (see Tables 1,2), suggesting that the decrease in the catalyst activity was resulted from the difference in surface property rather than textural structure.

The supports pretreated at different conditions were used to prepare NiMo catalysts, and the effect of pretreatment conditions on the catalytic activity was evaluated. It can be found that the NiMo/A-700-H-2 catalyst showed significantly higher HDS activity compared to the NiMo/A-700-2, indicating hydrothermal treatment can increase the catalyst activity through the recovery of silanol groups of the $\mathrm{SiO}_{2}$ spheres. As shown in Fig. 9, the catalyst activity increased with a decrease in calcination temperature and declined greatly when the calcination temperature reached $900{ }^{\circ} \mathrm{C}$. This was because the silanol groups lost during calcinations, especially at higher temperature, were just partly recovered in the hydrothermal treatment procedure, and the higher the calcination temperature, the more the silanol groups on the silica spheres were lost.



As shown in Fig. 10, the size and the dispersions of sulfided Mo species $\left(\mathrm{MoS}_{2}\right)$ of different supports were observed by using HRTEM. The size of active component $\mathrm{MoS}_{2}$ on $\mathrm{SiO}_{2}$ support is large and its dispersion is bad in Fig. 10a, in comparison with that in Fig. 10b, due to the weak interaction between metal oxide and $\mathrm{SiO}_{2}$ support (Scheffer et al. 1988), resulting in the low reaction rate constant $k$ (see Fig. 8). With the alumination of $\mathrm{SiO}_{2}$ supports, the dispersion of sulfided Mo species was improved significantly (Fig. 10b), and this is in accordance with the XRD results (see Fig. 6). It was suggested that the support, which is able to disperse the active components well, has relatively high catalytic activity.

\section{Conclusions}

NiMo catalysts supported on $\mathrm{SiO}_{2}$ opals aluminated by grafting with $\mathrm{Al}_{2} \mathrm{O}_{3}$ were prepared and characterized, and their HDS catalytic activity was tested. It was shown with the increase in grafted alumina content on the surface of $\mathrm{SiO}_{2}$, the surface properties changed from $\mathrm{SiO}_{2}$ to amorphous aluminosilicate and then to amorphous alumina. In line with this, the HDS rate constant $k$ of NiMo catalysts supported on the aluminated $\mathrm{SiO}_{2}$ followed a volcano curve when plotted as a function of alumina content. The alumination process of $\mathrm{SiO}_{2}$ opals by chemical grafting did not affect their well-defined pore structure, and alumination of the $\mathrm{SiO}_{2}$ surface led to an increase in the metal-support interaction and improved the dispersibility of the active species on the support surface.



Fig. 10 HRTEM images of NiMo catalysts supported on a A-700-H, b A-700-H-2 
Acknowledgements Financial support by the National Natural Science Foundation of China (Grant No. 91534120) and the Shanghai Petrochemical Company of Sinopec (under the contract number 30450127-13-ZC0607-0001) is greatly acknowledged.

Open Access This article is distributed under the terms of the Creative Commons Attribution 4.0 International License (http://crea tivecommons.org/licenses/by/4.0/), which permits unrestricted use, distribution, and reproduction in any medium, provided you give appropriate credit to the original author(s) and the source, provide a link to the Creative Commons license, and indicate if changes were made.

\section{References}

Baca M, Rochefoucauld E, Ambroise E, et al. Characterization of mesoporous alumina prepared by surface alumination of SBA15. Micropor Mesopor Mater. 2008;110:232-41. doi:10.1016/j. micromeso.2007.06.010.

Bagshaw SA, Pinnavaia TJ. Mesoporous alumina molecular sieves. Ang Chem Inter Ed Eng. 1960;35:1102-5. doi:10.1002/anie. 199611021.

Brandriss S, Margel S. Synthesis and characterization of selfassembled hydrophobic monolayer coatings on silica colloids. Langmuir. 1993;9(5):1232-40. doi:10.1021/la00029a014.

Breysse M, Afanasiev P, Geantet C, et al. Overview of support effects in hydrotreating catalysts. Catal Today. 2003;86:5-16. doi:10. 1016/S0920-5861(03)00400-0.

Breysse M, Geantet C, Afanasiev P, et al. Recent studies on the preparation, activation and design of active phases and supports of hydrotreating catalysts. Catal Today. 2008;130:3-13. doi:10. 1016/j.cattod.2007.08.018.

Cabrera S, Haskouri JE, Alamo J, et al. Surfactant-assisted synthesis of mesoporous alumina showing continuously adjustable pore sizes. Adv Mater. 1999;11(5):379-81. doi:10.1002/(SICI)15214095(199903)11:5<379:AID-ADMA379>3.0.CO;2-6.

Chen J, Ring Z. HDS reactivities of dibenzothiophenic compounds in a LC-finer LGO and $\mathrm{H}_{2} \mathrm{~S} / \mathrm{NH}_{3}$ inhibition effect. Fuel. 2004;83(3):305-13. doi:10.1016/j.fuel.2003.08.009.

Chen J, Yang H, Ring Z. Study of intra-particle diffusion effect on hydrodesulphurization of dibenzothiophenic compounds. Catal Today. 2005;109:93-8. doi:10.1016/j.cattod.2005.08.006.

Chen SL, Dong P, Yang GH, et al. Characteristic aspects of formation of new particles during the growth of monosize silica seeds. J Colloid Interf Sci. 1996;180(1):237-41. doi:10.1006/jcis.1996. 0295.

Chen SL. Preparation of monosize silica spheres and their crystalline stack. Colloids. Surf A Physicochem Eng Asp. 1998;142:59-63. doi:10.1016/S0927-7757(98)00276-3.

Cheralathan KK, Hayashi T, Ogura M. Post-synthesis coating of alumina on the mesopore walls of SBA- 15 by ammonia/water vapour induced internal hydrolysis and its consequences on pore structure and acidity. Micropor Mesopor Mater. 2008;116:406-15. doi:10.1016/j.micromeso.2008.05.001.

De Witte BM, Grobet PJ, Uytterhoeven JB. Pentacoordinated aluminum in noncalcined amorphous aluminosilicates, prepared in alkaline and acid mediums. J Chem Phys. 1995;99:6961-5. doi:10.1021/j100018a031.

Goldbourt A, Landau MV, Vega S. Characterization of aluminum species in alumina multilayer grafted MCM-41 using ${ }^{27} \mathrm{Al}$ FAM(II)-MQMAS NMR. J Phys Chem B. 2002;107(3):724-31. doi:10.1021/0217132.

Góra-Marek K, Derewiński M, Sarv P, et al. IR and NMR studies of mesoporous alumina and related aluminosilicates. Catal Today. 2005;101:131-8. doi:10.1016/j.cattod.2005.01.010.
Hensen EJM, Poduval DG, Magusin PCMM, et al. Formation of acid sites in amorphous silica-alumina. J Catal. 2010;269:201-18. doi:10.1016/j.jcat.2009.11.008.

Jun S, Ryoo R. Aluminum impregnation into mesoporous silica molecular sieves for catalytic application to Friedel-Crafts alkylation. J Catal. 2000;195(2):237-43. doi:10.1006/jcat.2000. 2999.

Klimova T, Calderón M, Ramírez J. Ni and Mo interaction with Alcontaining MCM-41 support and its effect on the catalytic behavior in DBT hydrodesulfurization. Appl Catal A Gen. 2003;240:29-40. doi:10.1016/S0926-860X(03)00503-9.

Landau MV, Dafa E, Kaliya ML, et al. Mesoporous alumina catalytic material prepared by grafting wide-pore MCM-41 with an alumina multilayer. Micropor Mesopor Mater. 2001;49:65-81. doi:10.1016/S1387-1811(01)00404-8.

$\mathrm{Li} \mathrm{Z}$, Gao L, Zheng S. Investigation of the dispersion of $\mathrm{MoO}_{3}$ onto the support of mesoporous silica MCM-41. Appl Catal A Gen. 2001;236:163-71. doi:10.1016/S0926-860X(02)00302-2.

Liu Z, Chen SL, Dong P, et al. Diffusion coefficient of petroleum residue fractions in a $\mathrm{SiO}_{2}$ model catalyst. Energ Fuels. 2009;23:2862-6. doi:10.1021/ef801100v.

Márquez-Alvarez C, Žilková N, Pérez-Pariente J, et al. Synthesis, characterization and catalytic applications of organized mesoporous aluminas. Catal Rev. 2008;50:222-86. doi:10.1080/ 01614940701804042.

Mokaya R, Jones W. Grafting of Al onto purely siliceous mesoporous molecular sieves. Phys Chem Chem Phys. 1999;1:207-13. doi:10.1039/A807919F.

Mokaya R. Post-synthesis grafting of Al onto MCM-41. Chem Commun. 1997;22:2185-6. doi:10.1039/A705340A.

Morris SM, Fulvio PF, Jaroniec M. Ordered mesoporous aluminasupported metal oxides. J Am Chem Soc. 2008;130:15210-6. doi:10.1021/ja806429q.

Nava R, Ortega RA, Alonso G, et al. CoMo/Ti-SBA-15 catalysts for dibenzothiophene desulfurization. Catal Today. 2007;127:70-84. doi:10.1016/j.cattod.2007.02.034.

Rayo P, Ramirez J, Rana MS, et al. Effect of the incorporation of Al, $\mathrm{Ti}$, and $\mathrm{Zr}$ on the cracking and hydrodesulfurization activity of NiMo/SBA-15 catalysts. Ind Eng Chem Res. 2009;48:1242-8. doi:10.1021/ie800862a.

Ryoo R, Kim MJ. Generalised route to the preparation of mesoporous metallosilicates via post-synthetic metal implantation. Chem Commun. 1997;22:2225-6. doi:10.1039/A704745B.

Scheffer B, Arnoldy P, Moulijn JA. Sulfidability and hydrodesulfurization activity of Mo catalysts supported on alumina, silica, and carbon. J Catal. 1988;112:516-27. doi:10.1016/00219517(88)90167-4.

Venezia AM, Murania R, La Parola V, et al. Post-synthesis alumination of MCM-41: effect of the acidity on the HDS activity of supported $\mathrm{Pd}$ catalysts. Appl Catal A Gen. 2010;383:211-6. doi:10.1016/j.apcata.2010.06.001.

Yada M, Kitamura H, Machida M, et al. Biomimetic surface patterns of layered aluminum oxide mesophases templated by mixed surfactant assemblies. Langmuir. 1997;13:5252-7. doi:10.1021/ la9704462.

Zepeda TA, Pawelec B, Fierro JLG, et al. Effect of Al and Ti content in HMS material on the catalytic activity of NiMo and CoMo hydrotreating catalysts in the HDS of DBT. Micropor Mesopor Mater. 2008;111:157-70. doi:10.1016/j.micromeso.2007.07. 025 .

Zhao XS, Lu GQ, Whittaker AK, et al. Comprehensive study of surface chemistry of MCM-41 using ${ }^{29} \mathrm{Si}$ CP/MAS NMR, FTIR, Pyridine-TPD, and TGA. J Phys Chem B. 1997;101:6525-31. doi:10.1021/jp971366+.

Zhou Z, Chen S-L, Hua D, et al. Preparation and evaluation of a wellordered mesoporous nickel-molybdenum/silica opal 
hydrodesulfurization model catalyst. Transit Met Chem. 2012a;37:25-30. doi:10.1007/s11243-011-9552-5.

Zhou Z, Chen SL, Hua D, et al. Structure and activity of NiMo/ alumina hydrodesulfurization model catalyst with ordered opallike pores. Catal Comm. 2012b;19:5-9. doi:10.1016/j.catcom. 2011.12.009.
Zukal A, Siklová H, Cejka J. Grafting of alumina on SBA-15: Effect of surface roughness. Langmuir. 2008;24:9837-42. doi:10.1021/ la801547u. 